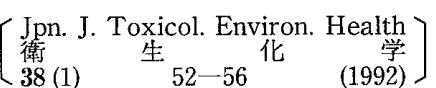

母乳中有機リン系白蟻防除剈の分析

\author{
吉田精作, ${ }^{a}$ 森口好孝, ${ }^{b}$ 小西良昌, ${ }^{a}$ 田口修三, ${ }^{a}$ 薬師寺積 $a$ \\ 大阪府立公衆衛生研究所, ${ }^{a}$ 大阪薬科大学 ${ }^{b}$
}

\title{
Analysis of Organophosphorus Termiticides in Human Milk
}

\author{
Seisaku Yoshida, ${ }^{a}$ Yoshitaka Moriguchi, ${ }^{b}$ Yosimasa Konishi, ${ }^{a}$ \\ Syuzo TAGUCHI $^{a}$ and Tsumoru YAKUShIJI ${ }^{a}$
}

Osaka Prefectural Institute of Public Health, ${ }^{a}$ 3-69, Nakamichi 1-chome, Higashinari-ku, Osaka 537, Japan and Osaka University of Pharmaceutical Science, ${ }^{\circ}$ 10-65, Kawai

2-chome, Matsubara 580, Japan

(Received July 9, 1991)

Chlorpyrifos and pyridaphention, organophosphorus insecticides, have been utilized for termite control as a substitute of chlordane from 1987 in Japan. In order to investigate the human exposure of these domestic pesticides, the analytical procedure for chlorpyrifos and pyridaphention in human milk sample, as an indicator of the domestic human exposure, was established, and the analyses of chlorpyrifos and pyridaphention levels in the breast milk of women living in the houses treated with termite control were carried out. Milk fat was extracted twice with diethylether-hexane from the milk sample. Defatting was performed by means of the Florisil dry column method; pesticides were eluted with $\mathrm{CH}_{3} \mathrm{CN}-\mathrm{H}_{2} \mathrm{O}=70-30$, and reextracted with $20 \%$ ether-hexane from acetonitrile layer. Chlorpyrifos and pyridaphention were analysed by gas chromatography (NPD-GC) equipped with a capillary column after clean-up on a silica gel column (chlorpyrifos was eluted with $4 \%$ ether-hexane, and pyridaphention with $75 \%$ etherhexane). The minimum detectable residues of chlorpyrifos and pyridaphention were $0.025 \mathrm{ppm}$ on fat basis in each by NPD-GC. Chlordane was detected in all 19 human milk samples (termiticide treated year, 1961-1988), however, chlorpyrifos and pyridaphention were both below the detection limit.

Keywords —- termiticide ; chlorpyrifos ; pyridaphention ; organophosphorus pesticide ; human milk; gas chromatography (NPD-GC) ; contamination ; human exposure

\section{緒}

\section{言}

環境污染物質の中でも代表的な PCBやDDTな ぞの有機塩素系化合物については多くの研究が行わ れ，環境中での挙動やヒト污染状況及びその経路が 明らかにされ，人体影響評価が精度よくできまるで

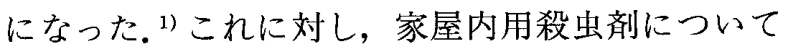
は，直接的経路により集中型ヒト污染を引き起こす ことが予想されるにもかかわらず，污染状況及びそ の経路などに不明な部分が多い. 白蟻防除剂のクロ ルデンはその代表例である．従来，そのヒト污染経 路は散布場所の床下から上昇してくるクロルデンの
エアロゾルを経気道的に摂取することが中心と考え られてきた. ${ }^{2}$ しかし, 最近我々は, クロルデンの精 白米への吸着という経路を明らかにし，このルート が居住者污染に大きく関与していることをつきとめ た。 ${ }^{3)}$ さに, クロルデン散布家屋に居住している授 乳婦の母乳を調査したところ, 対象者に比べてクロ ルデン濃度が数倍高い4)ことがわかった。

クロルデンが 1986 年に使用禁止となるにともな い，白蟻防除剤として有機リン䒺農薬のクロルピリ ホス,ピリダフェンチオンが使われるようになった. 有機りン系農薬は有機塩素系農薬に比較して環境中 で分解されや寸いとされ，クロルピリホス，ピリダ 
フェンチオンも同様と考えられるが, 家屋内系に関 するクロルピリホス，ピリダフェンチオンの人体污 染についての研究は未だ行われていない．また，人 体污染の指標となる母乳についてのクロルピリホ ス，ピリダフェンチオンの分析方法に関する報告も これまでに例がない。

本研究は, クロルデンの代替品であるクロルピリ ホス, ピリダフェンチオンに焦点を絞り，それらの 分析方法を確立し, 防除家屋居住者の活染状況につ いて，母乳を七ト污染指標として分析した，また同 時に, 母乳中のクロルデンの污染状況についても検 討した。

\section{実 験 方 法}

1. 試料及び試薬 母乳試料は 1989 年 11 月に 採取した.

エタノール，ジエチルエーテル，n-ヘキサン， ア セトン, 無水硫酸ナトリウムは和光純薬工業製残留 農薬試験用を使用した。シュウ酸カリウム 1 水和物 は和光純薬工業製特級を使用した。フフロリジルは和 光純薬工業製フロリジル PR を, シリカゲルはメル ク社製の Kieselgel 40（Art. 10180，70-230 mesh） を使用した。

2. ガスクロマトグラフィー＼cjkstart本体：HP 5711 A (NP-D). 分析カラム : DB-17 (J \& W 社) $30 \mathrm{~m} \times$ $0.32 \mathrm{~mm}$ i.d.（膜厚 $0.25 \mu \mathrm{m}$ ). 温度：Det. $250^{\circ} \mathrm{C}$ ； Inj. $200^{\circ} \mathrm{C}$; Col. $200 \rightarrow 280^{\circ} \mathrm{C}\left(4^{\circ} \mathrm{C} / \mathrm{min}\right)$. ガス: 総流量 $(\mathrm{He}) 23.5 \mathrm{ml} / \mathrm{min}$; キャリヤー $(\mathrm{He}) 0.7 \mathrm{~kg} /$ $\mathrm{cm}^{2}(2 \mathrm{ml} / \mathrm{min})$; メイクアップ $(\mathrm{He}) 48 \mathrm{ml} / \mathrm{min}$; $\mathrm{H}_{2} 4 \mathrm{ml} / \mathrm{min}$; Air $80 \mathrm{ml} / \mathrm{min}$. 注入量 : $2 \mu 1$.

3. 分析方法 母乳中クロルピリホス, ピリダ フェンチオンについての抽出・脱脂・精製過程を Chart 1 に示した.

哹脂肪の抽出方法は既報5)に準じた。ただし，抽 出は 2 回とし, 2 回目の抽出溶媒は $20 \%$ エーテルー へキサンとした。フロリジルドライカラムによる脱 脂操作も既報6に準じたが，アセトニトリル層から の転溶溶媒には $20 \%$ エーテルーヘキサンを用いた。
脱脂後のクリーンアップはパスツールピペットを利 用したシリカゲルミニカラム法7で行い, クロルピ リホスを $4 \%$ エーテルーヘキサンで，ピリダフェン チオンを $75 \%$ エーテルーへキサンで溶出した。

母乳中のクロルデンの分析方法は前車 ${ }^{4 a)}$ のと㧍 クである。

\section{結 果 及び考察}

\section{1. 分析方法の検討}

シリカゲルミニカラムにおける溶出試験におい て,クロルピリホスは $4 \%$ \%エーテルーへキサン $10 \mathrm{ml}$ で溶出が良好であり，ピリダフェンチオンは $75 \%$ エーテルーヘキサン $10 \mathrm{ml}$ で溶出した.

フロリジルドライカラムによる脱脂は有機塩素系 農薬の分析及び有機リン系農薬のフェニトロチオ ン, マラチオンの分析》において有効であることを 報告したが, 今回, 有機リン系農薬のクロルピリホ ス, ピリダフェンチオンについても有効かどうか検 討した.ピリダフェンチオンはエーテル可溶である がへキサンには僅かしか溶けず，そのためにアセ卜 ニトリルからへキサンへの転溶が難しいと考えられ た。そこでドライカラムに標準液を供し，30\%含水 アセトニトリル $150 \mathrm{ml}$ で溶出後, $10 \%$ エーテルーへ キサン $100 \mathrm{ml}$ で転溶（1回）を行ったところピリダ フェンチオンの回収率が約 $60 \%$ であったので, エー テル濃度を増加し，20\%エーテルーヘキサンで転溶 したところ良好な回収率（2 回平均でクロルピリホ ス $88.2 \%$ ，ピリダフェンチオン $93.2 \%$ )が認められ た.

牛乳にクロルピリホス, ピリダフェンチオンを添 加し脂肪の抽出工程から精製までの回収率を検討し た結果を Table Iに示す．結果は満足すべき回収率 であり,クロルピリホス, ピリダフェンチオンの両 方に関して適切な方法と考えられた. 牛乳に低濃度 添加したクロルピリホス $(0.002 \mathrm{ppm})$, ピリダフェ ンチオン $(0.004 \mathrm{ppm})$ のクロマトグラムを Fig. 1 に 示す． $4 \%$ エーテルーへキサンで溶出したクロルピ リホス画分は夾雑ピークがほとんどなく，75\%エー

TABLE I. Overall Recovery of Chlorpyrifos and Pyridaphention form Fortified Cow's Milk

\begin{tabular}{lccrccc}
\hline \hline \multirow{2}{*}{ Pesticide } & Milk & Fortified & \multicolumn{4}{c}{ Recovery (\%) } \\
\cline { 4 - 7 } & $(\mathrm{ml})$ & level (ppm) & \multicolumn{1}{c}{1} & \multicolumn{1}{c}{2} & 3 & Mean \pm S.D. \\
\hline Chlorpyrifos & 50 & 0.02 & 98.8 & 87.0 & 74.0 & $86.6 \pm 12.4$ \\
Chlorpyrifos & 50 & 0.002 & 94.9 & 98.2 & 98.0 & $97.0 \pm 1.85$ \\
Pyridaphention & 50 & 0.02 & 104.8 & 71.8 & 69.1 & $81.9 \pm 19.9$ \\
Pyridaphention & 50 & 0.004 & 92.1 & 95.6 & 107.6 & $98.4 \pm 8.13$ \\
\hline
\end{tabular}


テルーヘキサンで溶出したピリダフェンチオン画分 でもクロマトグラム上に夾雑ピークはあるものの定 量に妨害は認められなかった。

検出限界值については, 脂肪 $1 \mathrm{~g}$ を分析し最終液 量を $1 \mathrm{ml}$ とした場合, $\mathrm{GC} へ の$ 注入量 $2 \mu 1$ でクロマ
トグラム上 $0.05 \mathrm{ng}$ （fat basis：0.025 ppm）を検出 限界量とした. Fig. 1のクロマトグラムを見てもこ の值は十分検出可能であった. whole basisでの検 出限界值は脂肪含有量 $4 \%$ で $0.001 \mathrm{ppm}$ となる.

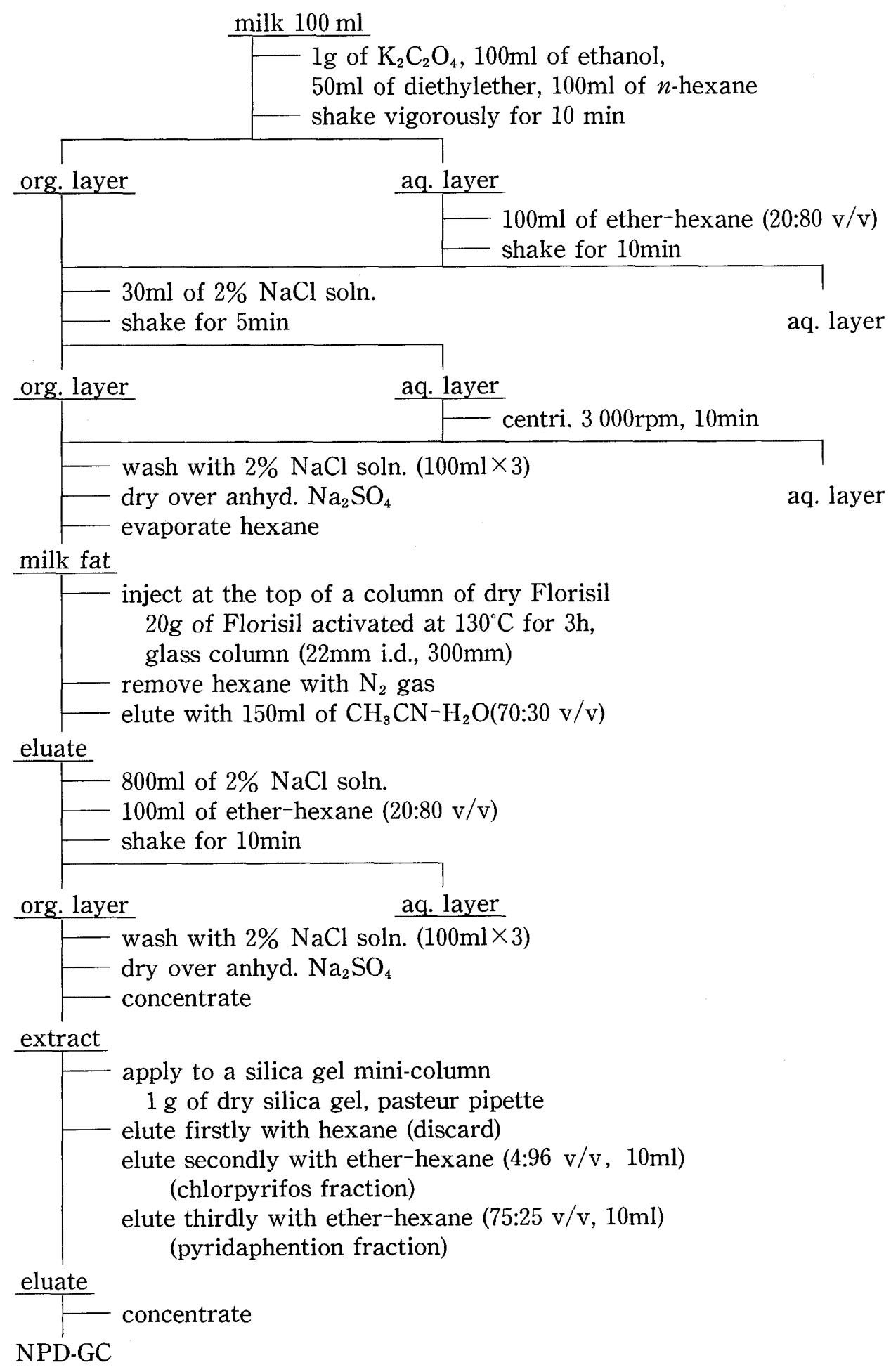

Chart 1. Analytical Procedure for Chlorpyrifos and Pyridaphention in Milk Samples 


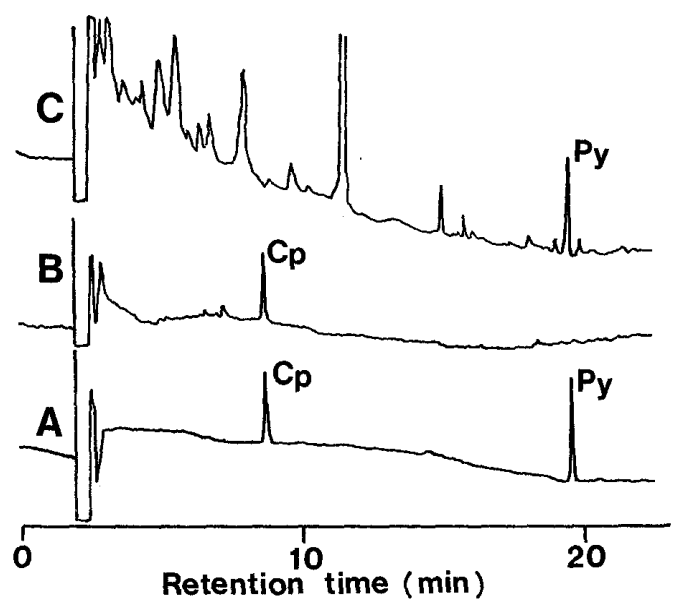

Fig. 1. Gas Chromatograms of Chlorpyrifos and Pyridaphention Standards Fortified into Cow's Milk

A : standards ; $\mathrm{Cp}$ (chlorpyrifos, $0.05 \mathrm{ng}$ ) ; Py (pyridaphention, $0.1 \mathrm{ng}$ ), B : chlorpyrifos fraction (fortified level : $0.002 \mathrm{ppm}$ on whole basis, recovery : $98.2 \%$ ), C: pyridaphention fraction (fortified level : $0.004 \mathrm{ppm}$ on whole basis, recovery : $92.1 \%$ ).

\section{の分析}

白蟻防除剤を散布した家屋に居住する（居住して いた）対象者 19 例の母乳脂肪について分析した結 果，クロルピリホス，ピリダフェンチオンともいず れの対象者からも検出されなかった (Table II)，母

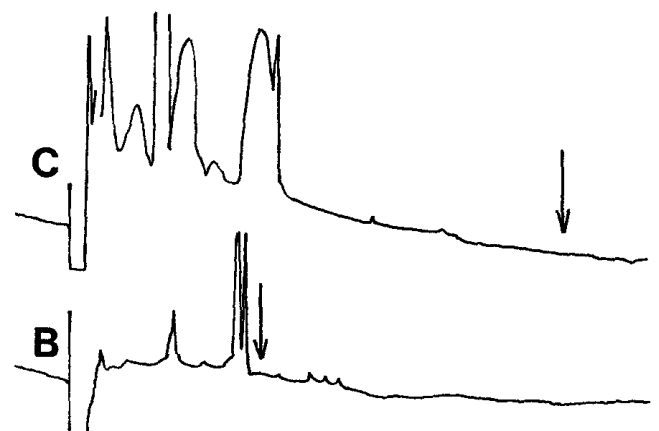

F1-2

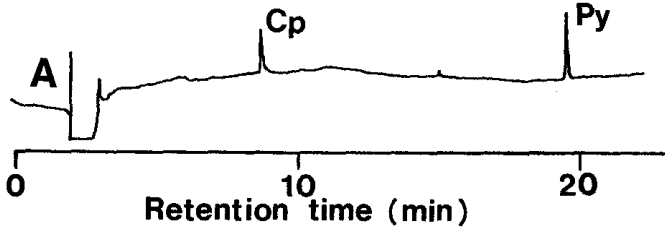

Fig. 2. Gas Chromatograms of Chlorpyrifos and Pyridaphention Fraction from Human Milk (sample No. 19)

A : standards ; $\mathrm{Cp}$ (chlorpyrifos, $0.05 \mathrm{ng}$ ) ; Py (pyridaphention, $0.1 \mathrm{ng}$ ), B : chlorpyrifos fraction, $\mathrm{C}$ : pyridaphention fraction.

乳の分析クロマトグラム (Fig. 2) は牛乳のものに比 べて夾雑ピークも多かったが，クロルピリホス，ピ リダフェンチオンの定量を妨害するピークは認めら れなかった。

Table II には母乳中のクロルデン濃度も示した.

TABLE II. Concentrations of Chlordane, Chlorpyrifos and Pyridaphention in Breast Milk of Mothers Living Termiticide Treated House (fat basis, ppm)

\begin{tabular}{rccccc}
\hline \hline No. & $\begin{array}{c}\text { Termiticide } \\
\text { treated year }\end{array}$ & $\begin{array}{c}\text { Living } \\
\text { periods }(\mathrm{y})\end{array}$ & Chlordane & Chlorpyrifos & Pyridaphention \\
\hline 1 & - & 15 & 0.171 & N.D. & N.D. \\
2 & 1961 & 22 & 0.063 & N.D. & N.D. \\
3 & 1970 & 3 & 0.064 & N.D. & N.D. \\
4 & 1970 & 0.3 & 0.051 & N.D. & N.D. \\
5 & 1974 & 14 & 0.061 & N.D. & N.D. \\
6 & 1975 & 13 & 0.108 & N.D. & N.D. \\
7 & 1977 & 10 & 0.060 & N.D. & N.D. \\
8 & 1978 & 11 & 0.216 & N.D. & N.D. \\
9 & 1979 & 4 & 0.163 & N.D. & N.D. \\
10 & 1980 & 8 & 0.215 & N.D. & N.D. \\
11 & 1981 & 2 & 0.112 & N.D. & N.D. \\
12 & 1981 & 7 & 0.173 & N.D. & N.D. \\
13 & 1982 & 6 & 0.197 & N.D. & N.D. \\
14 & 1983 & 2 & 0.067 & N.D. & N.D. \\
15 & 1983 & 5 & 0.094 & N.D. & N.D. \\
16 & 1984 & 1 & 0.167 & N.D. & N.D. \\
17 & 1984 & 6 & 0.061 & N.D. & N.D. \\
18 & 1987 & 0.1 & 0.100 & N.D. & N.D. \\
19 & 1988 & 1.5 & 0.028 & N.D. & N.D. \\
\hline N.D. $<0.025$ ppm. & & & & &
\end{tabular}


クロルデンの使用禁止年 (1986 年 9 月) 以降に白蟻 防除剂を散布した家屋の居住者 (No. 18 と No. 19) はクロルピリホス，あるいはピリダフェンチオンの 暴露をうけた（受けている）と考之られた。非散布 家屋居住者の母乳中クロルデン濃度は平均約 0.10 $\mathrm{ppm}$ (脂肪中) であり, ${ }^{4 b)}$ 虹取源はおもに魚介類であ る. ${ }^{8)}$ No. 18 の対象者の母乳中クロルデン濃度は低 く, 居住家屋にクロルデンの散布はなく, クロルピ リホスあるいはピリダフェンチオンが散布されたと 思われた。しかし，それらの母乳中濃度は検出限界 值以下であり，生体内蓄積性は極めて低いものと考 えられたが, 暴露後体内ではクロルピリホス, ピリ ダフェンチオンとも代謝を受けると考えられるの で，母物質がそのままの形で残っているかどうかは 暴露量との関係もありさらに研究が必要である。 な お, クロルピリホスについては, 散布作業者のよう な高濃度暴露の例では, 血液中クロルピリホスが散
布作業の翌朝にも代謝物と共に㭘出される事が報告 されている.9)

クロルデンは, 散布家屋では空気中や精白米中で

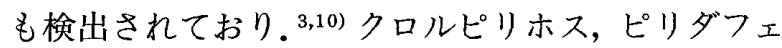
ンチオンについても，同様のことが考えられる．今 後增え続ける家屋内クロルピリホス・ピリダフェン チオン污染に関しては，ヒト污染経路の解明や暴露 後の人体影響評価について, 母乳の分析例を增やす とともに, 空気, ${ }^{12)}$ 保存食品等の分析や, 尿中代謝物 の検索も行い, 詳細な調查を進めることが重要と考 える.

謝辞本研究の遂行にご協力下さいました大阪 薬科大学 仙田恭子さんに感謝します。

本研究の一部は, 文部省科学研究費（重点領域研 究「人間環境系」)の援助を受けて行ったものであり， 関係各位に深謝します。

\section{引用 文 献}

1）薬師寺積，環境技術， 16，282（1987）.

2）薬師寺積, 田口修三, 西宗高弘, 日本食品衛生学会 第 54 回学術講演会要旨集, 神戸, 1987 年 10 月, P.50.

3）薬師寺積，小西良昌，田口修三，西宗高弘，田中凉一，食衛誌，32，78（1991）.

4） a) S. Taguchi, T. Yakushiji, Arch. Environ. Contam. Toxicol., 17,65（1988）； b ）小西良昌, 薬 師寺積，西宗高弘，國田信治，大阪府公衛研所報，食品衛生編，20，35（1989）。

5) T. Yakushiji, I. Watanabe, K. Kuwabara, S. Yoshida, J. Chromatogr., 154, 203 (1978).

6) T. Yakushiji, I. Watanabe, K. Kuwabara, S. Yoshida, S. Hori, S. Fukushima, T. Kashimoto, K. Koyama, N. Kunita, Arch. Environ. Contam. Toxicol., 8, 59 (1979).

7）小西良昌, 吉田精作, 栄食誌，40，375（1987）.

8）田口修三，小西良昌，薬師寺積，西宗高弘，田中凉一，食衛誌，30，526 (1989).

9）須永匡彦，吉田宗弘，上田照子，高坂祐夫，原 一郎，産業医学，31，142 (1989).

10）實成文彦, 浅川富美雪, 真鍋芳樹, 後藤 敦, 中鳴泰知, 日本公衛誌, 34, 302 (1987).

11）永美大志, 宇野正清, 陰地義樹, 田中 健, 山添 胖, 奈良県衛生研究所年報, 22, 93 (1987). 